Juan Carlos Amador ${ }^{1}$ jcarlosamador2000@yahoo.com
1 Profesor e investigador de la Universidad Distrital Francisco José de Caldas (Maestría en Comunicación-Educación y Licenciatura en Pedagogía Infantil). Director del Instituto para la pedagogía, la paz y el conflicto urbano (IPAZUD).

Fecha de recepción: 18 de octubre de 2013 / Fecha de aprobación: 8 de noviembre de 2013

\section{Aprendizaje transmedia en la era de la convergencia cultural interactiva}

\section{Resumen}

El artículo analiza las posibles relaciones entre el fenómeno transmedia y el aprendizaje en los niños y niñas contemporáneos; partiendo del presupuesto de Jenkins (2008), en el que la transmediación se inscribe en la convergencia mediática y tecnológica, el texto desarrolla tres grandes temáticas: la primera describe los principales aspectos de la convergencia cultural interactiva, contexto en el que se produce este fenómeno; la segunda expone los atributos del proceso transmedia, haciendo énfasis en los ambientes (ecología de medios) y la narrativa interactiva; y la tercera introduce algunas consideraciones, a manera de implicaciones pedagógicas, para fomentar aprendizajes en los niños y niñas, asunto que exige problematizar la noción de nativos digitales.

Palabras clave: transmedia, convergencia cultural interactiva, aprendizajes, niños y niñas.

\section{Transmedia Learning in the age of interactive cultural convergence}

\section{Summary}

The article discusses the possible relationships between the transmedia phenomenon and learning in contemporary children, based on the assumption Jenkins (2008), which is part transmediación media and technological convergence, the text develops three major themes: the first describes the main aspects of interactive cultural convergence, context in which this phenomenon occurs, the second exposes the attributes of transmedia process, stressing environments (media ecology) and interactive narrative, and the third introduces some considerations, as a pedagogical implications to encourage learning in children, an issue that requires problematize the notion of digital natives.

\section{Keywords: transmedia,} interactive cultural convergence, learning, boys and girls.

\section{Transmedia Aprendizagem na era da convergência cultural interativo}

Resumo

0 artigo discute as possiveis relações entre o fenômeno transmídia e aprendizagem em crianças contemporâneas, com base na suposição de Jenkins (2008), que faz parte transmediación mídia e convergência tecnológica, o texto desenvolve três temas principais: o primeiro descreve os principais aspectos da convergência cultural interativo, o contexto em que esse fenômeno ocorre, a segunda expõe os atributos do processo de transmídia, ambientes estressantes (ecologia da mídia) e narrativa interativa, eo terceiro apresenta alguns considerações, como um implicações pedagógicas para incentivar a aprendizagem em crianças, uma questão que requer problematizar a noção de nativos digitais.

Palavras-chave: transmídia, convergência cultural interativa, aprendizagem, meninos $e$ meninas. 


\section{Introducción}

$\mathrm{E}$ 1 presente trabajo tiene como propósito analizar los componentes sociales, comunicativos y cognitivos que constituyen actualmente el fenómeno transmedia, así como sus potencialidades para fomentar aprendizajes en los niños y niñas contemporáneos. De manera preliminar, se puede señalar que este suceso surge de la articulación progresiva de modelos narrativos hipertextuales y una serie de prácticas socio-culturales que circulan y se profundizan en, con y a través del mundo mediático y digital (Jenkins, 2008). $\mathrm{Al}$ parecer, el advenimiento de estas nuevas coordenadas espacio-temporales online (convergencia cultural interactiva), no sólo afecta los modos de socialización sino que configura otros modos de razonamiento del mundo de la vida en los sujetos y grupos.

Por esta razón, el "aprendizaje transmedia” es una propuesta que no pretende convertirse en un modelo ni en una fórmula para hacer efectivo el desempeño académico en escuelas y universidades. Se trata, más bien, del reconocimiento de una nueva esfera público-privada en la que están presentes sujetos, saberes, prácticas e intereses, la cual subyace de la convergencia cultural interactiva, esto es, modos de ser, pensar y actuar que emergen a partir del tránsito del receptor-usuario al prosumidor. Este tránsito está mediado por la participación de las personas comunes en la narrativa digital y en ambientes interactivos (ecología de medios) ${ }^{2}$.

El prosumidor (prosumer) no solo es consumidor sino también productor. Este cambio sugiere el advenimiento de nuevos atributos en el sujeto, que hacen posible otras maneras para el aprendizaje y la acción colectiva Dentro de estos atributos, se pueden destacar: la construcción de habilidades multitasking en espacios pantallizados e hiperconectados; la generación de otros sistemas de codificación y decodificación que hacen posible leer y escribir de manera hipertextual; y mecanismos de participación hipermediales e interactivos a través de proyectos colectivos que exigen colaboración y toma de decisiones.

Antes del surgimiento del fenómeno transmedia y sus vínculos con la educación, ha sido recurrente el planteamiento de puntos de vista que buscan vincular los medios y las tecnologías a la educación, tales como: el uso de las TIC para la enseñanza de contenidos académicos; el análisis crítico de medios; la educación virtual mediante la implementación de plataformas (Learning, Management System) para la implementación de cursos online multicanal y multimedia (e-learning, b-learning y multimodal); y la implementación de ambientes y objetos virtuales de aprendizaje. Sin embargo, como bien lo han señalado Inés Dussel (2006) y Joan Ferrés (2008), se trata del uso de artilugios (a veces muy sofisticados), que reproducen currículos y prácticas pedagógicas tradicionales.

También han aparecido durante los últimos años otras iniciativas en torno a las relaciones entre medios, tecnologías y educación, especialmente procedentes de las industrias culturales y las corporaciones transnacionales de software, hardware, telefonía móvil e Internet. En este grupo, las perspectivas no son muy distintas entre sí, pues, con frecuencia, sus orientaciones giran alrededor de promesas como estar conectados, tener amigos, vivir actualizados (accediendo a noticias, deportes, moda y recientemente aplicaciones móviles) así como divertirse en modo online a través de pasatiempos, juegos y mundos virtuales. Aunque también existe otro tipo de promesas, procedentes de activistas de la Web, como la generación de usuarios que participan en redes y comunidades, grupos que pueden gestar iniciativas sociales y gente común que puede compartir y crear.

Desde el punto de vista teórico, aquellos que han analizado la mutación de los medios y las tecnologías de información y comunicación, teniendo en cuenta los acontecimientos de la historia reciente, la diversidad de matrices culturales, la inestabilidad de los órdenes sociales y las lógicas geo-bio-noo-políticas ${ }^{3}$ de las sociedades contemporáneas, dan cuenta de la existencia de una revolución tecnológica que no determina lo humano ni el mundo de la vida (Castells, 2006; Latour, 2005; Lévy, 2007).

Se trata, más bien, de un proceso de co-construcción en el que los sujetos inciden en la transformación de las tecnologías, y en el que éstas a su vez modifican los modos de ser, hacer y pensar de las personas. Según Martín-Barbero (2003),

2 La noción ecología de medios fue planteada tempranamente por Marshall McLuhan. Dada su pertinencia para el abordaje del fenómeno transmedia y sus relaciones con el aprendizaje, este tema será desarrollado más adelante.

$3 \mathrm{Al}$ respecto, es importante señalar que los análisis políticos originados en la teoría social contemporánea plantean la biopolítica (Foucault, 2005), como un proceso de control sobre el cuerpo social, en el que están presentes la gubernamentalidad del sujeto, el territorio y la población. La noopolítica (Deleuze, 2006), implica el control de las pasiones, los conocimientos y los deseos, en el contexto de sociedad posfordista. 
la clave de este proceso está en los usos y las apropiaciones que las personas comunes producen en su vida cotidiana al relacionarse en, con y a través de los medios. Esto supone transitar de los medios a las mediaciones ${ }^{4}$.

En esta dirección, son varias las perspectivas que, apartándose del análisis instrumental de los medios y las tecnologías, han abordado el problema de las tecnologías digitales atendiendo a la complejidad humana, social y política que configura la cultura popular, la cultura visual y, de manera más reciente, la cultura digital. A partir de esta marco de comprensión sobre lo cultural (más que sobre la cultura en singular), se ha planteado la necesidad de repensar la escuela, no sólo mediante el equipamiento tecnológico y el uso de las TIC para enseñar contenidos académicos, sino reconociendo el universo de aprendizajes invisibles (Cobo y Moravec, 2010) que las generaciones más jóvenes adquieren en su condición prosumer y a través de su participación en la convergencia cultural.

Los planteamientos que se presentarán a continuación se enmarcan en estas preocupaciones. Se apoyan en los hallazgos de la tesis doctoral titulada Infancias, comunicación y educación: análisis de sus mutaciones. El propósito de la investigación fue comprender las mutaciones culturales (repertorio cultural televisivo y filmográfico dirigido a los niños y niñas) y las mutaciones comunicacionales (experiencia de niños y niñas en la comunicación digital interactiva) durante el período 19922012 en Colombia, con el fin de establecer sus implicaciones en la educación y el gobierno de la infancia. El estudio se apoyó metodológicamente en el análisis semiótico audiovisual procedente de la perspectiva de Roland Barthes (1980), y de la etnografía virtual (Hine, 2003).

Aunque no se hará alusión a los resultados del estudio en sentido estricto ${ }^{5}$, se desarrollará, tal como se anunció al inicio, un análisis del fenómeno transmedia (categoría emergente de la investigación) y sus relaciones posibles con los procesos de aprendizaje en el mundo escolar. Para tal efecto, se tratarán tres grandes temáticas: la convergencia cultural interactiva, escenario en el que surge el suceso transmedia ${ }^{6}$; los atributos de la transmedia, haciendo énfasis en los ambientes y la narrativa; y el aprendizaje, problematizando su carácter social, comunicativo y cognitivo así como el despliegue de la subjetividad del sujeto que aprende.

\section{Convergencia cultural interactiva}

Algunos pensadores de fines de siglo XX e inicios del siglo XXI, han mostrado otras facetas de esta nueva era que van más allá de las polarizaciones. Pierre Lévy (2004, 2007), propone observar la realidad contemporánea como un ecosistema de carácter social, técnico y cultural que modifica las condiciones de existencia de las personas, instituciones y sectores. Esta modificación está asociada con la emergencia de nuevas dimensiones de la realidad que incluyen atributos como lo virtual, lo digital y lo interactivo. Este fenómeno, al que denomina programa de la cibercultura, plantea un desafío fundamental: la inteligencia colectiva ${ }^{7}$.

Por su parte, ubicado en una línea comunicacional-semiótica, Carlos Scolari (2008) señala que en el inicio del nuevo milenio se observa un tránsito de las mediaciones a las hipermediaciones. Según el investigador argentino, los aportes de Martín-Barbero

4 Es necesario plantear de manera preliminar que la teoría de Martín-Barbero (2003), se basa en el tránsito de los medios a las mediaciones, esto es, de los aparatos a los procesos. Bajo este presupuesto, introduce conceptos como socialidades, sensibilidades y tecnicidades.

5 Los resultados de la investigación serán publicados mediante el formato de libro. En el momento de la escritura de este artículo la publicación se encuentra en prensa.

6 Vale la pena señalar que en el texto se emplearán los términos transmedia y transmediación. La génesis del primero está sutilmente relacionada con la expresión inglesa Mass Media, la cual ha sido abordada por la sociología a través de la tradición de estudios sobre medios de comunicación de masas, y por la comunicación, al referir al público y las audiencias. El segundo término alude al campo de lo mediático, perspectiva ampliamente desarrollada por Henry Jenkins (2008). Aunque se pueden buscar diferencias más finas, el texto se referirá con frecuencia al término transmedia, dado su interés por establecer puentes con la perspectiva ecología de medios.

7 En la respuesta a la pregunta de Pierre Lévy (2004), ¿qué es la inteligencia colectiva?, se destacan tres elementos claves que sirven como punto de partida para el desarrollo de esta propuesta. En primer lugar, se trata de una inteligencia repartida en todas partes, valorizada constantemente, coordinada en tiempo real y conducente a movilizaciones efectivas. En segundo lugar, su objetivo principal es el reconocimiento y enriquecimiento mutuo de las personas (no el culto de comunidades fetichizadas), y en tercer lugar, también puede ser entendida como un conjunto de energías y experiencias humanas desafortunadamente desperdiciadas que, teniendo el potencial para la movilización, suelen despreciarse. 
(2003) sobre la existencia de una matriz cultural que se ha sedimentado en el tiempo, a través de los usos y apropiaciones de los medios (cine, radio-teatro, prensa, telenovela, música negra, etc.), y que ha configurado progresivamente una suerte de hibridez cultural en América Latina y el Caribe, han adquirido nuevas características en la era de la Internet ${ }^{8}$.

Desde una perspectiva especialmente relacionada con la epistemología y los llamados estudios Ciencia, Tecnología y Sociedad (CTS), Bruno Latour (2005) explora las relaciones entre sujetos y objetos a través de lo que llama Teoría del Actor Red (TAR). Esta relación plantea que los objetos no son meros accidentes del mundo social, sino que se convierten en mediadores, capaces de participar en la agencia que el sujeto ejerce a través de sus prácticas y los sistemas de significado que recrea constantemente mediante la cultura.

En conclusión, los planteamientos de la cibercultura, las hipermediaciones y la TAR, en medio de sus diferencias, coinciden en plantear que, tanto en el carácter fenoménico del mundo contemporáneo como en sus marcos comprensivos-explicativos, subyacen tres registros fundamentales que permiten entender la relación entre comunicación, medios y tecnologías digitales frente a las transformaciones sociales y subjetivas del sujeto: otros modos de asumir la realidad; nuevas formas de gestionar la participación; y una ruptura de la totalización mediante la creación interactiva.

En esta línea de discusión, se puede señalar que las aproximaciones teóricas sobre convergencia no son abundantes, pero algunas de ellas proporcionan ideas ilustrativas sobre fenómenos emergentes que vinculan medios, prácticas sociales y matrices culturales (cercanas al enfoque CTS). Además de la importancia que adquiere la interconexión de los canales de distribución (plataformas) y de los dispositivos (en red), como ecosistemas que actualmente tramitan la vida de los niños y niñas; la digitalización de los medios ha provocado agencias sociales y culturales, preferiblemente asociadas con la participación y la generación de proyectos colectivos.

Lo más importante de estas manifestaciones colectivas de la sociedad contemporánea, a juicio de Henry Jenkins (2008), es que el advenimiento de esta convergencia mediática está dando lugar a la generación de culturas participativas. Aunque se trata de comunidades de usuarios que, motivadas inicialmente por el entretenimiento, consumen, producen y distribuyen contenidos propios y ajenos, estas experiencias sociales pueden llegar a convertirse progresivamente en proyectos alternativos a las hegemonías políticas, cognitivas y estéticas que han encontrado en la Web su principal superficie de control y reproducción.

La convergencia, comprendida por Jenkins (2008) como "cultura de convergencia mediática”, supone la existencia de un flujo de contenidos que se apoya en múltiples plataformas mediáticas, en la cooperación entre múltiples industrias mediáticas y en el comportamiento migratorio de las audiencias mediáticas. Estas audiencias, según el investigador del MIT, están dispuestas a ir casi a cualquier parte en busca del tipo deseado de experiencias de entretenimiento (2008, p. 14). Esto significa que la nueva circulación de los contenidos mediáticos depende de la participación activa de los consumidores, quienes pueden llegar a establecer conexiones entre contenidos mediáticos dispersos por distintos medios, canales e interfaces.

Sin afirmar que estas definiciones no sean válidas, y que seguramente proporcionan marcos explicativos claves para entender la fuerza del mundo mediático en la actualidad, es necesario introducir otros elementos que permitan precisar qué es la convergencia cultural y cuáles son sus implicaciones en la educación, la economía, la política y la estética. Por ahora, una opción para explorar este camino es el reconocimiento de las intersecciones entre cultura popular, cultura visual y cultura digital. Quizás en estas intersecciones se comprendan mejor las relaciones emergentes entre convergencia, transmedia y educación.

De entrada, es posible afirmar que la cultura popular no es estática y que actualmente se está redefiniendo, dadas las influencias de la cultura visual y la cultura digital en su conformación. Las explicaciones teóricas, originadas en la antropología y los estudios culturales, suelen entender la cultura popular en tres ámbitos: la distinción entre cultura popular y cultura de élite; la cultura popular como referente de las comunidades originarias y de políticas operadas a través de los medios masivos; y la cultura popular híbrida en el contexto de la globalización y la mundialización de la cultura.

La cultura visual es un concepto desarrollado recientemente para referirse a la consolidación de la imagen como referente que

8 Estas nuevas características ya no están asociadas con los medios (analógicos) y sus implicaciones en la construcción de la nación, sino con un espacio denso en el que confluyen de manera asimétrica medios, mediaciones, sujetos, prácticas y productos culturales. Este espacio, que en principio tiene como telón de fondo al mundo Web 2.0 (ahora 3.0), muestra una complejidad de fenómenos en la que están presentes consumidores, productores, identidades nómadas, subjetividades emergentes, grupos espontáneos, proyectos sociales y políticos, así como agentes hegemónicos. 


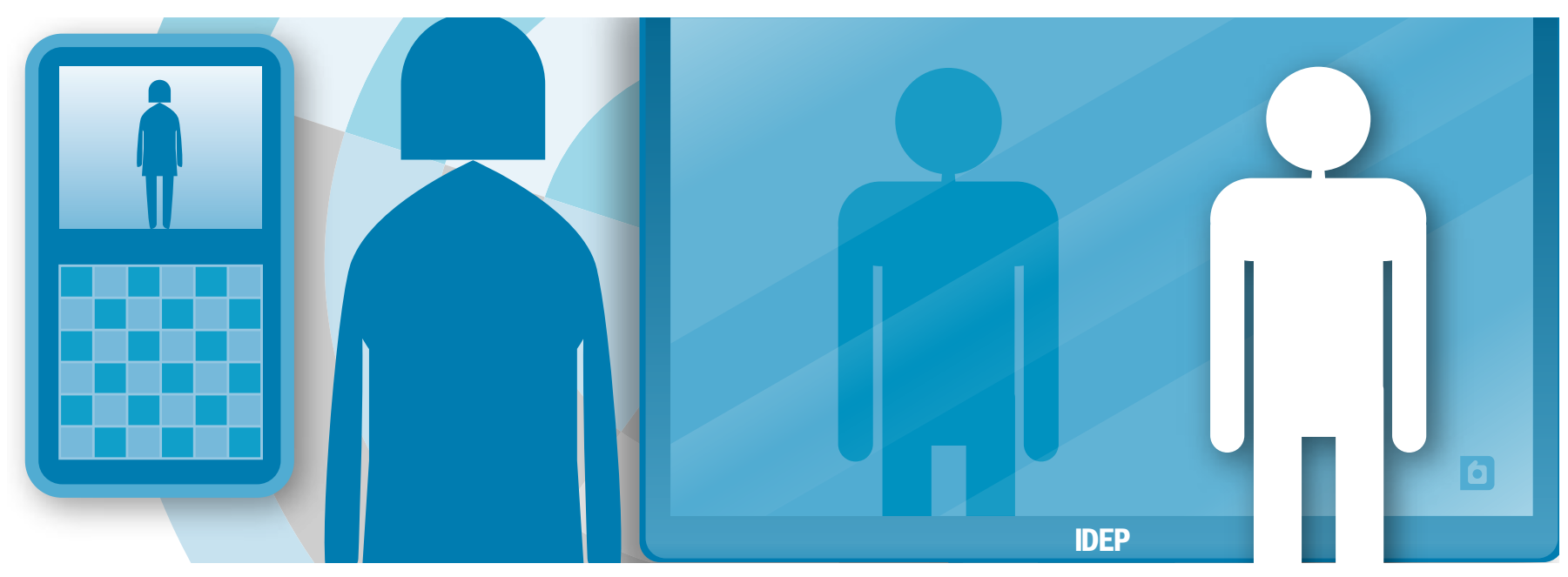

permite a las personas ingresar o salir del mundo social, político y cultural. Particularmente, autores como Arfuch y Devalle (2009), plantean que se trata de evidenciar la consolidación progresiva de un régimen de visualidad con profundas implicaciones en el campo del diseño y su relación con el arte. Esta relación genera impactos contundentes en los cuerpos, los estilos de vida, las dinámicas urbanas y las relaciones sociales en el mundo digital.

Como se puede apreciar, el centro de gravedad de la cultura visual es la imagen. No es tanto un holograma como sí una experiencia con sustratos semiológicos y ontológicos, que ha adquirido progresivamente sus propios atributos. Por esta razón, la imagen no es la representación de un objeto ni la analogía de un pensamiento o de una situación de la vida. Es una reinvención de la realidad que se vale de la metáfora, la ficción y la imaginación. Según Arfuch y Devalle (2009), la imagen es lenguaje y su mayor fortaleza está en su carácter performativo.

Estas condiciones en las que ha surgido la cultura visual se traslapan con la cultura digital, al compartir la imagen como núcleo de la expresión y la comunicación. En tal sentido, la cultura digital es comprendida como un proceso de organización, producción y comunicación participativa, que se apoya no sólo en las tecnologías digitales sino en actitudes y posicionamientos éticos, cuyas orientaciones fomentan la construcción y distribución de la cultura (Casacuberta, 2003; Montagu, et al, 2004).

Esta manera de asumir la cultura cuenta con la comunicación como la mediación y el enlace privilegiado para favorecer la participación, la producción, la reproducción y la difusión de contenidos. Es una nueva manera de relacionarse con el mundo a partir de procesos de digitalización general, asociados con nuevos significados que se tejen en medio de la producción cultural contemporánea (Manovich, 2001).

En suma, apoyados en estos referentes, se puede señalar que la convergencia cultural es algo más que un simple cambio tecnológico. La convergencia cultural (mediática y tecnológica) altera la relación entre las tecnologías existentes, la industria, los mercados, los géneros y los públicos. En parte, obedece a un cambio cultural en el que se involucran el flujo de los medios en sus diversas expresiones, las arquitecturas comunicacionales, la proliferación de canales y redes, y la portabilidad de tecnologías digitales.

Sin embargo, es claro que la convergencia también está teniendo lugar en los intersticios de las tres culturas (popular, visual y digital). Lo popular ya no es solamente aquello que se consume masivamente conforme al poder del mercado o a los relatos nacionales impuestos por el gobierno o un sector de las élites. Lo popular actualmente se construye en la ecología de medios (McLuhan, 1996), los cuales fluyen múltiples, efímeros y cambiantes, a través de los entornos visual y digital que configuran los mundos de vida de las personas comunes.

Siguiendo a Martín-Barbero (2003), es evidente que lo popular se construye a partir de usos y apropiaciones de contenidos culturales, no solo a través de la recepción o de la imposición ideológica. En el contexto de la cultura visual y la cultura digital, los sujetos producen usos y apropiaciones a través de vínculos de distinta intensidad con la imagen, el diseño y la narrativa. Estos elementos aparentemente dispersos, logran una suerte de articulación progresiva que posibilita la configuración de ambientes e interfaces, capaz 
de propiciar la generación de lenguajes, formas de socialización y saberes colectivos. Esta intensidad se experimenta dependiendo de la distancia o acercamiento de los usuarios a dichos ambientes.

Los ambientes e interfaces son de diverso orden: la ciudad, el barrio o la vivienda; los museos, las salas de cine y los centros interactivos; las instituciones educativas (por ejemplo universidades y escuelas); los ambientes virtuales (ubicados en la interfaz del
PC, la tablet, el smartphone o el reproductor de video y música). En suma, la convergencia cultural es un fenómeno que vincula la construcción social y subjetiva de las personas con la narrativa (que fluye discontinua por cualquier tipo de interfaz) y su posibilidad de inmersión en el ambiente (ecología según McLuhan, 1996). Este escenario sugiere considerar la existencia de una convergencia cultural interactiva.

\section{Transmedia: entre ambientes y narrativas}

Henry Jenkins (2008), uno de los primeros en examinar este concepto, plantea que el proceso transmedia está asociado con relaciones y prácticas que conforman lo que denomina cultura participativa. En esta cultura están presentes viejos y nuevos medios, así como géneros, formatos y contenidos de diverso orden. Los consumidores, ahora convertidos también en "prosumers" (prosumidores $)^{9}$, establecen conexiones entre contenidos mediáticos dispersos, por ejemplo en literatura convencional, filmes, videojuegos, cómics y mundos virtuales. Se pueden destacar tres características fundamentales de su estructura y modo de funcionamiento.

En primer lugar, las transmediaciones hacen parte de industrias que, a través de la producción de una obra más que de un producto para vender, funcionan con el propósito de crear mundos con complejas estéticas y líneas narrativas que no se agotan en una entrega. Por esta razón, pueden producir varias versiones como "las partes" de la Guerra de las Galaxias (1977) o trilogías de culto como The Matrix (1999).

En segundo lugar, sus contenidos son tan elaborados que exigen del usuario explorar el mundo de diversas maneras con otros registros audiovisuales y digitales, por ejemplo a través de videojuegos, redes sociales, mundos virtuales, cómics y OVAS ${ }^{10}$. Obviamente, sus usuarios se convierten en públicos especializados que generan prácticas, las cuales pueden ir, desde ejercer el rol del fan, hasta crear tramas alternativas en comunidades de práctica y en medios divergentes. $Y$ en tercer lugar, sus narrativas contienen múltiples patrones comunicativos, capaces de garantizar identificaciones con todos los públicos, en particular con las generaciones más sensibles a la interactividad digital.

Jenkins (2008), considera que la narración contemporánea se ha convertido en el arte de crear mundos. A medida que los artistas y los productores van creando entornos que persuaden y que merecen la atención del usuario, éste último descubre que no puede explorarlo por completo en una sola entrega y que tal vez ni siquiera pueda conocerlo a profundidad a través de un único medio.

Por esta razón, el mundo es más grande que el filme y que los objetivos de la franquicia, asunto que se convierte en un reto, pues, en ocasiones, se vuelve una obsesión para los públicos. La polivalencia y el carácter transmediático de obras como The $\mathrm{Ma}$ trix (1999) o Harry Potter (2000), por ejemplo, permiten que sus usuarios sean parte del mundo y que coloquen en escena sus especulaciones y/o elaboraciones de diversas maneras.

Por supuesto que se trata de alteraciones no neutrales de la obra original, y que obedecen al ensanchamiento del capital

9 Como se señaló al inicio, el término prosumidor, también conocido como prosumer, es un neologismo formado a partir de la fusión de las palabras en inglés producer (productor) y consumer (consumidor). También suele asociársele con las palabras en inglés professional (profesional) y consumer (consumidor) (Toeffler, 1980 y 2009). Se trata de una actividad que agrega valor a un producto, servicio o al propio conocimiento. En relación con las nuevas formas de comunicación y las tecnologías digitales, la actitud prosumer sólo funciona mediante redes de colaboración, las cuales agregan valor de manera colectiva, incentivando la innovación y compartiendo conocimientos que pueden llegar a acelerar los ciclos económicos y tecnológicos.

10 Su original en inglés es original video animation. Se trata de productos para públicos expertos, los cuales sólo son producidos y distribuidos mediante formato de video. Más adelante, se profundizará este tema, el cual está ligado a sagas y propuestas metaseriales, especialmente pertenecientes a los géneros anime y manga.

11 La economía afectiva es una tendencia transnacional en la que el posicionamiento de una marca es más importante que la novedad de un producto a ser vendido. El marketing contemporáneo plantea forjar la reputación de la marca, no sólo mediante una transacción individual, sino mediante la suma total de interacciones con el cliente a través de puntos de contacto: "Se trata de construir comunidades de marca como medio para fomentar la fidelidad del consumidor [...] por eso el propósito es tener audiencias activas" (Jenkins, 2008, pp. 76-77). 
transnacional y su profundización en la economía afectiva o de las emociones ${ }^{11}$. Su punto crucial ha sido introducir a las personas en estos mundos, no sólo para que invadan las taquillas de la sala de cine en los estrenos mundiales, sino para que accedan al mundo ofrecido mediante cualquiera de sus medios.
Es por esta razón que la aproximación al fenómeno transmedia no puede hacerse exclusivamente a través del análisis de las industrias culturales. Aquí se propone analizar otras dimensiones posibles, apoyados en los conceptos de ecología de medios y narración interactiva.

\section{Ambientes (ecología de medios) y transmedia}

Como se ha señalado hasta el momento, el fenómeno transmedia es un proceso de articulación intertextual y de multitrayectoria de contenidos, los cuales se encuentran dispersos por distintos medios. Dicha articulación no la establecen necesariamente los diseñadores y desarrolladores, sino los prosumidores, quienes, además de actuar individualmente, logran mejores modos de articulación trabajando de manera colectiva y colaborativa. En consecuencia, una dimensión fundamental para el despliegue de la transmediación son los ambientes.

Algunos autores han planteado conceptos como ambiente y entorno, en relación con los medios y las tecnologías digitales, con el fin de hacer énfasis en la calidad de la interfaz para alcanzar mejores niveles de interactividad. También hay quienes plantean el ambiente como un flujo de información que permite, dependiendo de su accesibilidad, la realización de ciertas tareas (procedimentales) y hasta experiencias sociales que facilitan la articulación de lenguajes, saberes y prácticas. Sin embargo, dado que las transmediaciones circulan por múltiples medios, quizás una de las mejores aproximaciones a este fenómeno la plantea Marshall McLuhan (1996), a través de la expresión ecología de medios.

Para McLuhan (1996), el surgimiento de las tecnologías asociadas con los medios hace que se generen ciertos efectos en los

ambientes comunicativos en los que están presentes las personas. Lo más importante de este fenómeno es que la ecología de medios se complejiza en la medida que las tecnologías tienden a convertirse en expresiones y hasta prolongaciones del hombre. Por esta razón, en los ambientes se producen remediaciones (Bolter, 2000), comprendidas como manifestaciones humanas (extensiones y sistemas nerviosos) que adquieren trayectorias propias, y cuyos contenidos pueden fluir, combinarse, remezclarse y reinventarse ${ }^{12}$.

Lo anterior permite entender la importancia que contienen los ambientes en el fenómeno transmedia. El prosumidor explora los contenidos que le interesan a través de diversos soportes y plataformas mediáticas. Por esta razón, su recorrido puede ser en espiral, laberíntico, rizomático y/o acrobático, al estilo del surfista. Su capacidad no sólo está en descifrar los contenidos, sino en producir sentido intertextual y abductivo, a tono con el contexto comunicativo, pues no siempre va de lo general a lo particular o viceversa. Debe encontrar los rastros, los vestigios, las pistas y las tramas que se explicitan de manera directa o metafórica en las dimensiones temporales y espaciales de los medios, así como en los intersticios de éstos.

12 Esto significa que la ecología de medios no sólo se refiere a la existencia de interfaces amigables con los usuarios para que éstos puedan acceder, por ejemplo, al sistema operativo de Microsoft o Linux, o a las aplicaciones móviles para smartphone. Se trata de una suerte de ubicuidad que acompaña la vida de las personas en todo tiempo y lugar (anytime/anywhere, según Bolter, 2000), y que permite abordar situaciones de la vida cotidiana, resolver problemas, generar iniciativas y hasta promover proyectos colectivos-colaborativos.

13 Por su parte, Jerome Bruner (2002), sostiene que el pensamiento humano es ante todo narrativo. Aunque en sus primeros trabajos planteó una marcada distinción entre pensamiento paradigmático y pensamiento narrativo, más adelante ratificó la hegemonía del segundo en todas las formas sociales. Según Bruner, los modos de razonamiento de las personas, tanto en situaciones simples de su vida cotidiana como en experiencias especiales (de felicidad, dolor o deseo), emplean formas narrativas diversas con el fin de producir sentido a sus relaciones consigo mismo, con los otros y con el mundo. La construcción de significados surge de la narración, de la continua actualización de historias y de complejidades que suelen incorporarse a los relatos mediante la problematización constante de las tramas. Finalmente, Hayden White (1992), sostiene que es necesario, en el contexto de la narrativa de ficción y la narrativa histórica, establecer los aspectos constitutivos de la narrativización de hechos reales. La narrativización es un suceso en el que el narrador se vuelve invisible y la narración fluye libre, tratando de dar autonomía a los acontecimientos, los cuales parecen hablar por sí mismos. White (1992), agrega que la fuerza de la narrativa no está en sus recursos discursivos de carácter semiológico o pragmático, sino en la atmósfera moral y social en la que acontece. 


\section{Narrativa interactiva}

Uno de los aspectos medulares del fenómeno transmedia es la narración interactiva. Parece extraño emplear la palabra interactiva a un género que, en sí mismo, guarda un carácter transaccional en la génesis de su intención comunicativa. Al respecto, es importante recordar, a través de áreas del conocimiento como la filosofía, la psicología y la historia, que la narrativa es un atributo humano que no sólo se centra en la expresión, sino en la posibilidad de construir la identidad personal y colectiva mediante la resignificación permanente de los acontecimientos humanos.

Por ejemplo, Paul Ricoeur (2004) plantea, en el contexto de su hermenéutica filosófica, que la identidad narrativa es un proceso que surge del entrecruzamiento permanente entre el relato histórico y el relato de ficción. Más allá de identidades preestablecidas y modos de conocimiento canónicos que fijan al sujeto en una ontología del cogito, la narración y la profundización de la narratividad hacen posible la construcción de identidades móviles (ipseidad según Ricoeur), que favorecen el tránsito del sí mismo al mundo del otro ${ }^{13}$.

Estos referentes muestran el valor que ha adquirido en la escena intelectual el tema de la narrativa, así como sus potencialidades para comprender la condición humana. Así mismo, en el campo transmedia, la narrativa también ha logrado un protagonismo importante, especialmente frente a la emergencia de nuevos productos culturales que articulan la narrativa audiovisual con la narrativa digital. Manovich (2001), ha preferido llamarle a esta novedad mediático-comunicativa "narrativa interactiva".

De manera más precisa, apoyados en Scolari (2013:25), transmedia alude a una especial forma narrativa que se expande en diversos sistemas de significación de tipo verbal, icónico, audiovisual o interactivo, así como en distintos medios, por ejemplo el cine, la televisión, el videojuego, el cómic o el teatro. Sin embargo, es importante señalar que no se trata de una simple adaptación de lenguajes, proceso muy recurrente en la transferencia de historias de la literatura al cine.

Se trata más bien de una construcción de mundos que se apoya en distintos lenguajes y medios. Por esta razón, dependiendo del ambiente, surgen relatos, tramas, personajes y desenlaces distintos, sin perder los hilos conductores de una matriz original. Esta red de relaciones profundiza y expande la narrativa, promueve la inmersión de los prosumidores en la ecología de medios y fomenta la generación de contenidos creativos.

Recientemente han aparecido proyectos que se aproximan a estas nuevas condiciones mediáticas. El proyecto Soft Cinema (2005), animado por Manovich y otros, es una experiencia interactiva que incluye medios digitales, digital art, diseño arquitectónico, software social e instalaciones. Comprendido como un "proyecto artístico new media de carácter colaborativo", Soft Cinema se ha convertido en un ícono de la actitud prosumer. En su estructura se mezclan la producción de diseñadores, desarrolladores y artistas, así como la generación de narrativas paralelas de cientos de internautas, adscritos por diversas vías al proyecto ${ }^{14}$.

En el contexto colombiano existen proyectos que han empezado a mostrar el valor social y político de la narrativa transmedia ${ }^{15}$. Un ejemplo de esta inusual forma de contar historias lo ilustra el proyecto Los Once, Como un cuento de hadas (2012). Esta es la expresión que emplea el colectivo colombiano Sharpball para titular una obra representativa de un género emergente al que llaman novela gráfica de ficción histórica ${ }^{16}$. Se trata de 11 ratones, protagonistas del relato, que personifican a cada uno de los desaparecidos de la toma del $\mathrm{Pa}$ lacio de Justicia en 1985 por parte del movimiento guerrillero M19, y de la retoma por parte del ejército colombiano ${ }^{17}$.

En conclusión, la narrativa digital es constitutiva de la transmedia. Su mayor atracción y potencia es que se trata de una narrativa

14 Todas las características del Proyecto Soft cinema, así como algunas reflexiones de Manovich, pueden ser visualizadas en el sitio http://www.softcinema.net/?reload

$15 \mathrm{Al}$ respecto, es importante aludir a los proyectos de Jaime Alejandro Rodríguez Gabriela Infinita, Golpe de gracia y Narratopedia (Rodríguez, 2008, 2011).

16 El colectiva Sharpball está constituido por Andrés Cruz y los hermanos Miguel y José Luis Jiménez.

17 En un período de tiempo de 28 horas, los ratones deben luchar por sobrevivir a un conjunto de hechos catastróficos que van dando lugar a la destrucción del Palacio de Justicia. Según su sitio Web, la construcción de la narrativa requirió una indagación rigurosa de noticias y columnas de prensa sobre este acontecimiento, así como el estudio de libros que narran, desde distintos puntos de vista, este episodio de la historia reciente de Colombia (Palacio sin Máscara de Germán Castro Caicedo, y Palacio de Justicia: una tragedia colombiana de Ana Carrigan, entre otros). Así mismo, señalan, fue necesario reconstruir las historias en diálogo permanente con los familiares de los desaparecidos.

La narrativa se compone de una animación que mezcla cómic silente, blanco y negro y animalización (al estilo Maus de Art Spielgelman). Además de los ratones, quienes representan a las víctimas, aparecen cuervos (guerrilleros) y criaturas que cambian de forma en cada uno de los episodios (militares), al estilo de "la nada" en La Historia Interminable de Michael Ende. El proyecto logró ser financiado mediante la estrategia crowdfunding (fondos apoyados por multitudes), gracias a su presencia dinámica en redes sociales y plataformas como YouTube y Vimeo. Actualmente ha logrado un mayor despliegue, gracias a su ubicuidad móvil en Appsolution, asegurando mayores niveles de interactividad con el público. 
en constante movimiento y transformación, al transitar por diversos lenguajes, medios y plataformas. A través de su puesta en escena, surgen nuevas pragmáticas, estilos y expresiones (Rodríguez, 2011). Sin embargo, más allá de la fascinación por las novedades que subyacen en sus modos de expresión, el carácter narrativo de la transmedia fomenta la creación colectiva y hace posible formas de empoderamiento del usuario (prosumidor), que pueden incidir en la construcción de su identidad personal y colectiva.

\section{Aprendizaje transmedia y subjetividades}

Marc Prensky (2002), planteó que los nativos digitales, sujetos que han nacido y crecido a partir de la década del noventa del siglo pasado, no sólo poseen formas distintas de relacionarse con el mundo (en oposición a los inmigrantes), sino que contienen una suerte de plasticidad social, cognitiva y emocional que les facilita adaptarse al cambio tecnológico. Más allá de la relación nativos digitales-entorno tecnológico, la cual es recurrente en las ofertas del mercado de tecnologías digitales, es importante aludir a otros argumentos que contribuyen a caracterizar a las generaciones más jóvenes. Aquí se han identificado dos argumentos: el proceso de refiguración y la construcción de la subjetividad.

En relación con el proceso de refiguración, vale recordar que Norbert Elías (1998), planteó cómo, en el proceso civilizatorio del mundo occidental, se fue cristalizando un lento proceso de aprendizaje entre padres e hijos. Esta vinculación asimétrica que consolidó la idea moderna de la familia, fue conquistada gracias a un mecanismo de figuración que articuló relaciones de poder y modos de regulación del tiempo y el espacio, tanto en el niño como en los padres. En este proceso de larga duración, las instituciones de educación y protección (cruciales en el proyecto de modernidad) adoptaron este modelo, el cual se convirtió hasta finales del siglo XX en la base de las sociedades adultocéntricas.

Los cambios de carácter geopolítico, económico y socio-cultural que se empezaron a producir a finales del siglo XX, demuestran el tránsito de una matriz estado-céntrica a otra socio-céntrica, así como la caída de la figura weberiana de la "jaula de hierro", al decir de Richard Sennett (2006). En esta progresiva desinstitucionalización, las figuras del padre, el Estado y, en general, de las instituciones, las cuales proceden de la misma raíz figurativa, se debilitan y traen consigo un proceso de refiguración.

Los niños y niñas que tramitan sus formas de socialización, sensibilización y acceso al saber, mediante la convergencia cultural, mediática y tecnológica, están viviendo esta refiguración, la cual, en medio de sus cruces y tensiones con el mercado y las industrias culturales, hasta ahora inicia. Quizás, como lo explica Elías (1998), es una construcción de larga duración que no sólo afecta la socio-génesis, sino la psico-génesis de la estructura social.

Así mismo, la noción de nativos digitales también puede ser problematizada mediante el concepto de subjetividad. Si se parte de entender la subjetividad como un proceso de constitución del sujeto, la cual está vinculada con la construcción de un yo (situado e historizado) en relación con un complejo social, político y cultural, que contiene tensiones y contradicciones, es posible afirmar que en medio de estas condiciones epocales se está produciendo una redefinición ontológica y humana del sujeto, que se expresa de manera más contundente en los cuerpos, lenguajes y experiencias de los niños y niñas. Aunque estas dos ideas requerirían mayor profundidad, pues no son parte del propósito de este trabajo, aportan otros elementos al debate de los nativos digitales.

De otra parte, uno de los puntos de inflexión fundamentales para problematizar el aprendizaje en la era de la convergencia cultural, es el concepto de ambiente. No obstante, es preciso señalar que la vieja expresión ambiente de aprendizaje, la cual suele referir a un conjunto de condiciones favorables incorporadas al aula para lograr motivación y buen desempeño en los estudiantes, no da cuenta de la potencia que hoy adquiere esta noción. Los ambientes de aprendizaje, en relación con el fenómeno transmedia, vinculan la ecología de medios, esto es, un conjunto de lenguajes, saberes y prácticas que surgen a partir de la coexistencia de medios, mediaciones y contenidos que rodean la vida de los niños y niñas. Sin duda, el ambiente de aprendizaje va más allá del aula y de la escuela.

Por esta razón ya no es posible considerar que los niños y niñas generen aprendizajes y adquieran conocimientos mediante su vinculación al ritual de la enseñanza, en el que un profesor transmite contenidos, al mejor estilo del viejo esquema comunicativo emisor- receptor-broadcasting. Los ambientes, especialmente aquellos que están dotados de imágenes, hipertextos, movimiento, paisajes sonoros y narrativas, hacen posible que estos 


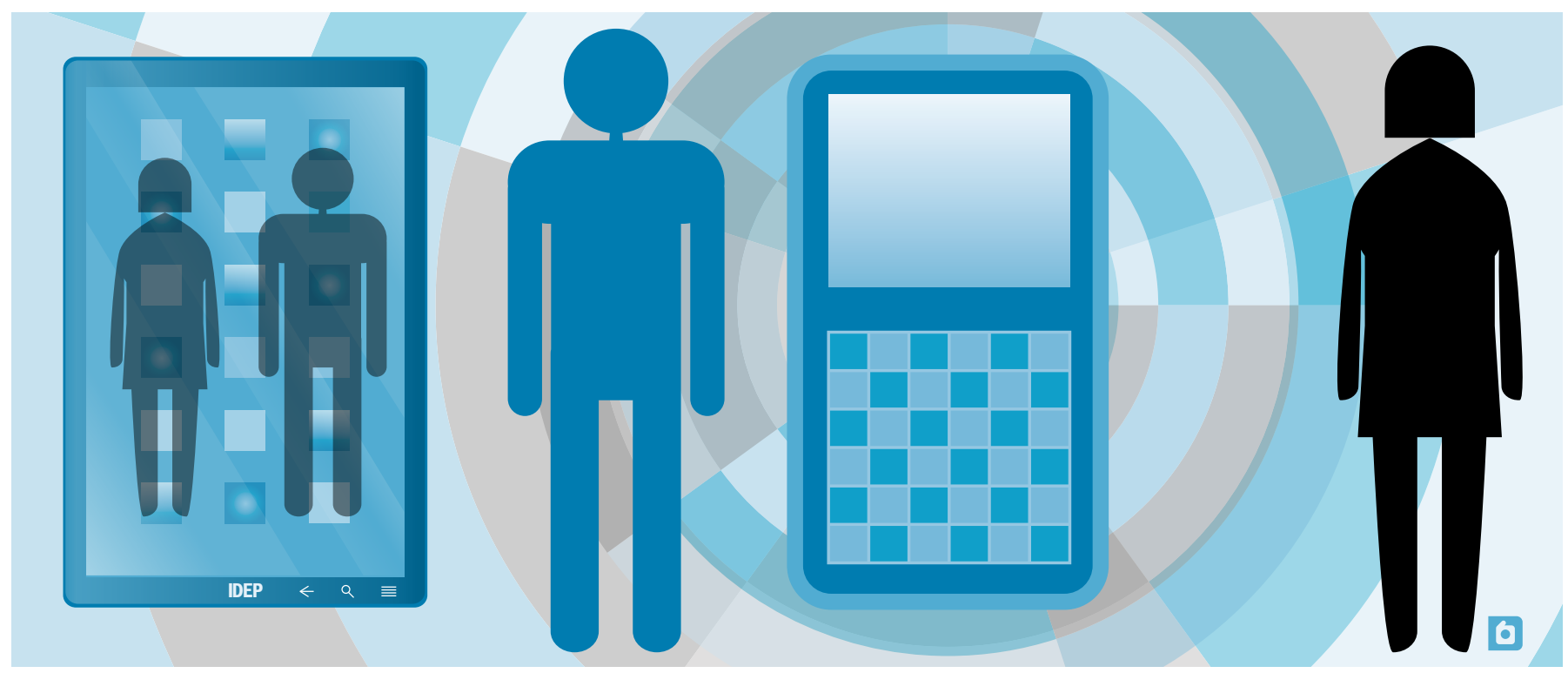

desarrollen tres procesos claves que favorecen su aprendizaje: la interactividad; la socialización de saberes; y la participación colaborativa para la generación de acciones colectivas.

Como bien lo ha señalado Alessandro Baricco (2008), el nativo digital (a quien prefiere llamarle bárbaro), surfea en la cresta de la ola, lugar en el que domina la espectacularidad: "[...] la espectacularidad es una mezcla de fluidez, de velocidad, de síntesis, de técnica que genera una aceleración [...] el bárbaro piensa menos, pero piensa en redes indudablemente más extensas. Efectúa en horizontal el camino que nosotros estamos habituados a imaginar en vertical" (2008, p. 159).

En tal sentido, lo aprendido como prosumidor en la convergencia cultural lo puede llevar a desplegar diversos modos de interactividad: interactividad con los contenidos (los cuales están dispersos por diversos medios y expresados en distintos lenguajes); interactividad con el profesor (a quien es preferible considerarle mediador del aprendizaje); e interactividad con otros (compañeros de clase, redes de interesados en el tema y/o comunidades de práctica expertas en el tema).

En relación con los contenidos, el aprendizaje transmedia plantea un giro pedagógico imprescindible. Se trata de transitar del contenido guiado por el texto escolar y el conocimiento enciclopédico del profesor (los cuales generalmente son enseñados para que queden intactos), al desarrollo de capacidades en el estudiante relacionadas con el rastreo y tratamiento de la infor- mación que circula por diversos medios, plataformas y soportes textuales, audiovisuales, sonoros, icónicos y digitales. El desarrollo de estas capacidades debe partir de los aprendizajes invisibles de los niños y niñas, pues, en su vida cotidiana, leen, escriben y razonan hipertextualmente.

Según Guillermo Orozco (2010), se trata de desarrollar capacidades para seleccionar información desde las pantallas, a nivel instrumental, semántico y pragmático. Esto indica que el nuevo paradigma educativo debe transitar del "uso de las TIC" al uso de las pantallas, en clave de ecología de medios. Por esta razón, se requiere la generación de prácticas pedagógicas que fomenten la exploración de diversas fuentes de información que están ubicadas en diversos formatos, lenguajes y medios (multipantalla) a los que se puede tener acceso por diversas vías. En consecuencia, la comunicación en el aula (ahora colaboratorio) se diversifica, pasando del monocanal al multicanal y multimedial, desarrollando formas de comprensión de la realidad mediadas por lo oral, lo visual, lo audiovisual y lo escrito.

La interactividad entre estudiante y profesor también cambia. Si el nuevo paradigma educativo asume que la realidad del nativo digital está enmarcada en la convergencia cultural, la cual incluye otras convergencias, como la lingüística, la cognitiva, la estética y la situacional (Orozco, 2010, p. 273), evidentemente el profesor ya no es un instructor o alguien que transmite conocimientos. Ahora debe asumir el rol de mediador del aprendizaje a partir de la comunicación transmediática. 
La interactividad entre profesor y estudiantes, entonces, debe transitar del monolingüismo (propio de la instrucción de la escuela moderna) al plurilingüismo y al diálogo de saberes. No se trata de exigirle al profesor que se convierta en diseñador o programador, pero sí que adquiera las capacidades necesarias para identificar las rutas posibles de aprendizaje, de modo que explore y halle los lugares relevantes en donde estén presentes contenidos de su área de conocimiento. Mejor aún si esos contenidos están expresados de manera textual, audiovisual, icónica o digital. Así mismo, es deseable que estos contenidos estén presentes en diversos medios, plataformas y soportes.

El tercer tipo de interactividad (entre pares, entre interesados y entre expertos), también cambia, pues, evidentemente, va más allá del aula de clase. Lo primero que cambia es la condición del grupo: transita de un conglomerado de alumnos que recibe clases, a una comunidad de práctica que explora, experimenta, debate y socializa lo que aprende. Por esta razón, la interactividad no sólo fluye entre compañeros de clase sino entre otras comunidades, por ejemplo niños, niñas y jóvenes que se encuentran en red, y que potencialmente les interesan los temas abordados. O expertos que están ubicados en cualquier parte del mundo, de quienes se puede aprender más de lo alcanzado.

El segundo atributo del aprendizaje transmedia, en la dimensión de los ambientes de aprendizaje y la ecología de medios, es la posibilidad de la socialización de saberes. Como es sabido, la cristalización de un aprendizaje se logra una vez la persona se pone en escena y expresa lo que sabe. Aunque parece un asunto de sentido común, es lo que menos se hace en la escuela moderna. Generalmente, en este tipo de educación, el alumno repite lo que el texto escolar describe o lo que el profesor ha enseñado. Los trabajos y tareas adolecen de audiencias, pues estos son presentados al profesor, quien, en su soledad, determina si el alumno aprueba o reprueba.

En tal sentido, es importante remitirse a dos reflexiones que han sido abordadas por expertos en el campo de la Educomunicación. El primero es Joan Ferrés (2008), quien propone asumir la educación como un proceso que ha de articular lo intelectual-racional con lo emocional-persuasivo. Por esta razón, plantea, apoyado en estudios recientes en el campo de las neurociencias, el cultivo del conocimiento en las personas se desarrolla por la vía de las pasiones, esto es, a través de un proceso de incorporación de las personas en torno a ciertos temas y problemas del conoci- miento, que hace posible el desarrollo de habilidades, disciplina e intereses. Esto se logra en la medida que las personas socializan (de modo off line y online) lo que saben.

Por su parte, Orozco (2010), señala que el uso de diversas pantallas (convergentes) con fines educativos, por ejemplo el uso de bases de datos articulados con el uso de sitios Web, no sólo hace posible almacenar información con el fin de exponerla, sino que permite intercambiarla para avanzar hacia procesos de producción de contenidos. En suma, el aprendizaje actualmente requiere que las personas expresen (por diversos medios y canales) lo que van conociendo. Sin embargo, lo más importante es que deben socializar con audiencias que progresivamente se van constituyendo en comunidades. Su potencial es la construcción de lo común, esto es, una condición fundamental para la generación de acciones colectivas.

Finalmente, el tercer atributo de los ambientes de aprendizaje se centra en la participación colaborativa. Como es sabido, el campo de la pedagogía, desde el punto de vista teórico, ha hecho esfuerzos importantes durante las últimas tres décadas por modificar la hegemonía del paradigma del aprendizaje memorístico (propio de la escuela moderna). Algunos ejemplos que ilustran estos esfuerzos son las teorías del aprendizaje significativo y el aprendizaje por descubrimiento. Aunque, recientemente, han aparecido otras que proponen nuevos elementos, a propósito del uso de las TIC, los ambientes virtuales de aprendizaje, las plataformas interactivas y las tecnologías móviles, tales como blended learnign, smart learning y movil learning.

A partir de la propuesta de aprendizaje significativo, en adelante se observa la necesidad de articular el aprendizaje con la comunicación, no sólo desde el punto de vista instrumental, sino especialmente a través de dimensiones políticas, éticas y estéticas. Por esta razón, algunas teorías del aprendizaje centradas en la comunicación en el aula (Edwards y Coll, 2006), evidencian que el aprendizaje en el mundo escolar no sólo requiere de formas creativas de interactividad, sino especialmente de mecanismos de participación de la comunidad, expresados en conversaciones, problematizaciones, análisis de contextos (textuales, audiovisuales, icónicos, digitales, etc.), e incluso mediante su vinculación a rituales.

En conclusión, los ambientes de aprendizaje no son el aula ni tampoco la escuela. En el aprendizaje transmedia, el ambiente está en la ecología de medios, que, según McLuhan (1996), no sólo es la coexistencia de medios y contenidos, los cuales están dispersos por 
diversos lugares y tiempos, sino el intento de la sociedad por hacer de las tecnologías extensiones del cuerpo y el pensamiento humanos.

En esta ecología de medios, la cual se configura en el mundo en el que surfean los niños y niñas contemporáneos (bárbaros), es posible generar capacidades y procesos de empoderamiento para reconstituir la esfera pública. Sin embargo, se trata de una tarea que requiere de comunidades académicas reflexivas, argumentativas y críticas, proceso que debe ser emprendido con criterio ético, de cara a la reificación de la práctica pedagógica de los maestros y maestras.

\section{Referencias}

Amador, J.C. (2012). Infancias, comunicación y educación: análisis de sus mutaciones. Tesis para optar por el título de Doctor en Educación, no publicada. Bogotá: Doctorado Interinstitucional en Educación. U. Distrital, U. Pedagógica Nacional y U. del Valle.

Arfuch, L., y Devalle, V. (Comps.). (2009). Visualidades sin fin. Imagen y diseño en la sociedad global. Buenos Aires: Prometeo Libros.

Baricco, A. (2008). Los Bárbaros, ensayo sobre la mutación. Barcelona: Anagrama.

Barthes, R. (1980). La cámara lúcida. Nota sobre la fotografía. Barcelona: Paidós.

Bruner, J. (2002). Actos de significado, más allá de la revolución cognitiva. Madrid: Alianza.

Bolter, J., y Grusin, R. (2000). Remediation. Understanding New Media. USA: MIT Press

Casacuberta, D. (2003). Creación colectiva. En Internet el creador es el público. Barcelona: Gedisa.

Castells, M. (2006). La era de la información. Economía, sociedad y cultura. Vol. I La sociedad red. México: Siglo XXI.

Corea, C., y Lewcowicz, I. (2004). Pedagogía del aburrido. Escuelas destituidas, familias perplejas. Buenos Aires: Paidós.

Edwards, D., y Mercer, N. (2006). El conocimiento compartido. El desarrollo de la comprensión en el aula. Buenos Aires: Paidós.

Edwards, D., y Coll, C. (2006). Enseñanza, aprendizaje y discurso en el aula. Aproximaciones al estudio del discurso educacional. Madrid: Fund. Infancia $\mathrm{y}$ aprendizaje.
Elías, N. (1998). La civilización de los padres y otros ensayos. Bogotá: Norma.

Ferrés, J. (2008). La educación como industria del deseo. Un nuevo estilo comunicativo. Barcelona: Gedisa.

Hine, C. (2002). Etnografía virtual. Barcelona: UOC.

Jenkins, H. (2008). Convergence Culture. La cultura de la convergencia de los medios de comunicación. Barcelona: Paidós.

Latour, B. (2005). Reensamblar lo social. Una introducción a la teoría del actor-red. Buenos Aires: Manantial.

Lévy, P. (1999) ¿Qué es lo virtual? Barcelona: Paidós.

Lévy, P. (2004). Inteligencia colectiva. Por una antropología del ciberespacio. Washington: Organización.

Lévy, P. (2007). Cibercultura. La cultura de la sociedad digital. Barcelona: Anthropos, U. Autónoma Metropolitana.

Manovich, L. (2001). El lenguaje de los nuevos medios de comunicación. La imagen en la era digital. Barcelona: Paidós.

Martín-Barbero, J. M. (2003). De los medios a las mediaciones. Comunicación, cultura y hegemonía. Bogotá: Convenio Andrés Bello.

Martín-Barbero, J. M. (2004). Tecnicidades, identidades, alteridades: desubicaciones y opacidades de la comunicación en el nuevo siglo. Guadalajara: ITESO.

McLuhan, M., y Nevitt, B. (1996). Comprender los medios de comunicación. Las extensiones del ser humano. Barcelona: Paidós.

Mead, M. (1980). Cultura y compromiso. Buenos Aires: Granica. 
Montagu, et al. (2004). Cultura digital. Comunicación y sociedad. Buenos Aires: Paidós.

Orozco, G. (2001). Audiencias: mediaciones y televisión pública. En Rincón, O. (Comp.). Televisión pública: del consumidor al ciudadano. Bogotá: Convenio Andrés Bello.

Orozco, G. (2010). Entre pantallas: nuevos roles comunicativos y educativos de los ciudadanos. En Aparicci, et al. Educomunicación: más allá del 2.0. Barcelona: Gedisa.

Ortiz, R. (2004). Mundialización y cultura. Bogotá: Convenio Andrés Bello.

Prensky, M. (2002-octubre). Digital natives, digital immigrants. On The horizon, Vol. 9, No 5, MCB University Press.
Ricoeur, P. (2004). Tiempo y narración I. México: Siglo XXI.

Rodríguez, J. A. (2011). Narrativas del ciberespacio. En Rodríguez, J. A. (Ed.). Narratopedia. Reflexiones sobre narrativa digital, creación colectiva y cibercultura. Bogotá: Universidad Javeriana.

Scolari, C. (2008). Hipermediaciones. Elementos para una teoría de la comunicación digital interactiva. Barcelona: Gedisa.

Scolari, C. (2013). Narrativas transmedia. Cuando todos los medios cuentan. Barcelona: Planeta. 